\title{
Diseño y construcción de un equipo de registro y análisis de potenciales evocados somatosensoriales de la médula espinal - Revisáo Aberta
}

\author{
Thais B.O. Fragelli*
}

\section{SÍNTESE}

$\mathrm{O}$ artigo pretende divulgar um equipamento para obtenção e análise do potencial evocado somatossensorial com menor custo e que facilitaria a utilidade clínica e cirúrgica. Os autores realizam uma revisão sobre potencial evocado contextualizando e atualizando o leitor acerca da temática e da importância da sua medição na prática clínica e cirúrgica. Descreve ainda sobre os procedimentos para a construção do equipamento, o desenvolvimento de hardware e do software. Sua conclusão atenta para o fato de redução de custo e um aparelho com mesma eficiência daqueles já existentes no mercado.

\section{RESUMO}

Resumo claro e adequado dentro dos aspectos formais.

\section{INTRODUÇÃO}

O artigo delimita muito bem a questão do potencial evocado, sua importância na prática clínica e sua necessidade em situaçōes cirúrgicas que requeiram o monitoramento dos sinais.

$\mathrm{Na}$ descrição da morfologia do potencial evocado somatossensorial (PES) sugere-se aos autores que remetam a uma figura para melhor visualização das ondas $\mathrm{N}$ e P. Ao citar as siglas EEG e EMG sugere-se sua descrição por extenso.

Os conceitos foram bem apresentados, justificando a importância do tema principalmente quando referencia a utilização do potencial evocado e a necessidade de equipamentos de custo mais barato e com qualidade para a prática clínica. Os autores não detalham as formas de medidas atuais, apenas citando a EEG e EMG de uma forma muito célere.

Enfatiza a importância da mensuração do potencial evocado, relata dificuldade de mensuração pelos ruídos de captação, necessitando da filtragem do sinal.

Os autores não apresentam estudos anteriores sobre o mesmo tema. Esta descrição enriqueceria ainda mais o trabalho, principalmente se fosse apresentado as vantagens e desvantagens dos equipamentos e justificando a necessidade de se desenvolver um novo equipamento.

Destaca muito bem a importância da filtragem e da promediação na captação do PES e do processo para obtenção da estimulação até a saída em papel.

Relata o problema quando descreve: "El costo comercial del equipo requerido para el uso clínico de los PES sobrepasa la capacidad de muchas instituciones de salud en el tercer mundo, lo cual excluye a muchos pacientes de los beneficios descritos".

Ao final descreve o objetivo: "En el presente trabajo se describe el diseño y construcción de un equipo constituido por hardware y software para obtener los PES a un muy bajo costo con el nivel de calidad requerido."

\section{MÉTODO}

O início da metodologia poderia ser iniciado

* Fisioterapeuta especialista em Fisioterapia Neurofuncional, Mestre em Psicologia Social (UnB), Doutoranda em Ciências da Saude (UnB), Brasília-DF, Brasil. 
com a descrição de o que é requerido para mensuração de um potencial evocado somatossensorial seguido dos materiais utilizados para a construção do equipamento.

Os diagramas e as figuras estão claras. Talvez o acréscimo de mais imagens quanto a interface tornaria a descrição mais enriquecedora.

$\mathrm{Na}$ descrição do Hardware e do Software, os autores expóem sequencialmente os tópicos sem uma numeração que indique a hierarquia dos títulos o que dificulta para o leitor (ex. hardware, módulo de estimulação). A inserção de uma numeração sequencial ou relacionar no início do tópico de hardware, como uma introdução, o que o compóe (ex. o hardware compóese de 2 módulos: estimulação, aquisição). $\mathrm{O}$ mesmo pode-se observar na descrição do software.

Os autores relatam o programa que foi desenvolvido software (Matlab), as vantagens que o software trouxe para a interface e a promediaçáo, mas náo o detalha impossibilitando de certa forma a replicação.

Para o protocolo clínico o autor informa o consentimento, mas não ficou claro se o trabalho foi submetido a um comitê de ética.

O teste está adequado podendo também ser acrescentado o teste em nervo mediano para comparaçóes, ou ainda, deixar claro nos objetivos que o equipamento se restringe ao potencial evocado somatossensorial lombar.

O protocolo clínico deveria detalhar a variação de intensidade utilizada que estão descritas no resultado, como também, a justificativa para a não utilização de parâmetros acima de $90 \mathrm{~V}$.

\section{RESULTADOS}

Os autores relatam o custo final do aparelho no entanto, seria interessante relacionar em tabela os materiais utilizados à parte talvez com o custo para confirmar seu objetivo comparando o que se tem no mercado e o proposto.

A descrição das ondas $\mathrm{N}$ e $\mathrm{P}$ poderiam ser alocadas na introdução considerando que não são resultados e sim fazem parte da leitura do PES.
Os autores relatam que estimulaçóes altas foram utilizadas para indivíduos com grande massa corporal, porém não fica claro se este dado foi retirado de alguma literatura ou se os autores realizaram este teste. Caso tenha sido retirado da literatura, falta a referência, se os autores que realizaram, não foi descrito na metodologia.

No parágrafo seguinte os autores relatam que os resultados obtidos condizem com os parâmetros de indivíduos normais e, prosseguem dizendo que são para os sujeitos que participaram dos testes do equipamento proposto, no entanto, no teste descrito há apenas um sujeito. Da maneira colocada, parece que foram feitos testes com mais sujeitos, porém, estes não foram descritos no artigo.

\section{DISCUSSÃO E CONCLUSÕES}

O estudo generaliza a aplicação do aparelho, no entanto, o teste apresentado relata apenas o monitoramento de sinais lombares. Há a comparação com equipamentos do mercado sem o detalhamento. Descreve as vantagens do equipamento construído, porém, sem a comparação detalhada com o que existe de pesquisas na literatura e no mercado.

Os autores discutem as razóes para a obtenção dos resultados e sua conclusão responde a pergunta do estudo.

\section{REFERÊNCIAS BIBLIOGRÁFICAS}

Sugere-se aos autores que insiram referências mais atualizadas, principalmente de estudos sobre o tema proposto enfatizando o que se tem produzido no âmbito acadêmico. Há, no decorrer do texto, referências não numeradas como, por exemplo, onde se descreve o módulo de aquisição em que a referência Burr-Brown $^{\mathrm{TM}}$ não está numerada. Há momentos que os autores fazem afirmaçôes que não ficam claras se são de estudos já realizados.

O que se conclui é que o trabalho é de grande relevância necessitando de apenas alguns ajustes por parte dos autores. 